\title{
Box Plot
}

National Cancer Institute

\section{Source}

National Cancer Institute. Box Plot. NCI Thesaurus. Code C53326.

A graphical display of the distribution of a set of data using the median, quartiles, and the extremes of the data set. The box contains the values between the upper quartile and lower quartile, or $50 \%$ of the distribution. 